\title{
Asians Have More Perianal Crohn Disease and Ocular Manifestations Compared with White Americans
}

\author{
Bharati Kochar ${ }^{a, b}$ Edward L. Barnes ${ }^{a, b}$ Hans H. Herfarth ${ }^{a, b}$ \\ Christopher F. Martin ${ }^{a}$ Ashwin N. Ananthakrishnan ${ }^{c}$ Dermot McGovern ${ }^{d}$ \\ Millie D. Long ${ }^{a}$ b Robert S. Sandler ${ }^{a}$ \\ ${ }^{a}$ Center for Gastrointestinal Biology and Disease and ${ }^{\mathrm{b}}$ Multidisciplinary Center for Inflammatory Bowel Disease, \\ University of North Carolina, Chapel Hill, NC, 'Division of Gastroenterology, Massachusetts General Hospital, \\ Boston, MA, and d F. Widjaja Inflammatory Bowel and Immunobiology Research Institute, Cedars-Sinai Medical \\ Center, Los Angeles, CA, USA
}

\section{Keywords}

Asians · Crohn's disease $\cdot$ Immigrants · Inflammatory bowel disease $\cdot$ Race $\cdot$ Ulcerative colitis

\begin{abstract}
Background: Inflammatory bowel disease (IBD) is increasing in Asians. We sought to better understand differences in IBD between Asians and whites in the United States (US). Methods: We used data from the Sinai-Helmsley Alliance for Research Excellence cohort to assess disease characteristics for US-born Asians, Asian immigrants, and whites. We used bivariate analyses to describe clinical characteristics by race. We used logistic regression to determine baseline odds of immunosuppression and binomial regression to estimate risk ratios for worsening disease at follow-up. Results: We included 5,223 whites, 35 US-born Asians, and 81 Asian immigrants. Crohn disease (CD) was present in $64 \%$ of whites, $40 \%$ of US-born Asians, and $51 \%$ of Asian immigrants. At baseline, $58 \%$ of whites, $62 \%$ of US-born Asians, and $67 \%$ of Asian immigrants were in remission by disease activity in-
\end{abstract}

dex score $(p=0.238)$. There were no significant differences in $C D$ location and behavior or ulcerative colitis extent. Asians had significantly more perianal disease than whites (33 vs. $18 \%, p=0.007$ ). Asians were more likely to have ocular manifestations than whites (3.4 vs. $0.7 \%, p=0.022$ ). Asians were also significantly less likely to be depressed than whites ( 25 vs. $35 \%, p=0.022$ ). Adjusting for confounders, Asians had half the odds of being treated with biologics compared with whites (OR: $0.45,95 \% \mathrm{Cl}: 0.30-0.67)$. Adjusting for disease behavior and remission status, there were no differences in IBD-related surgery or hospitalization, new biologic or steroid prescription, or relapse rates between Asians and whites at follow-up. Conclusion: Asians are more likely to have perianal disease and ocular extraintestinal manifestations. After controlling for confounders, Asians were less likely to be treated with biologic agents. Despite this, there were no significant differences in outcomes over time between Asians and whites. Differences in disease phenotypes in Asians may reflect differences in genetics.

(c) 2017 S. Karger AG, Basel

\section{KARGER}

(c) 2017 S. Karger AG, Basel 
Asians are the fastest growing racial group in the United States (US) with a $43 \%$ increase in the population between 2000 and 2010 [1]. The incidence and prevalence of inflammatory bowel disease (IBD) is increasing in Asians across the globe [2-4]. Numerous studies describe disease characteristics in Asians residing in their native countries $[5,6]$. However, there are fewer studies of IBD in Asians in Western nations [7]. The published reports are primarily cross-sectional studies that describe the incidence and prevalence of IBD in Asians. A study of a pathology database reported that people with Indian names might have higher rates of IBD than other American populations [8]. A population-based study in Canada found that younger age at immigration increased the risk of IBD in immigrants, with Canadian-born children of immigrants assuming local incidence rates of IBD [9].

The literature describing disease activity and longitudinal outcomes in Asian IBD patients is sparse. One study suggested that Asians might have a milder disease course than whites or Hispanics [10]. However, the data are conflicting. Pediatric studies suggest that South Asians had higher rates of Crohn disease (CD) as well as more complicated disease $[11,12]$. A recent large metaanalysis reported that although Asians may have more upper gastrointestinal and perianal CD than whites, they had lower rates of surgery despite no significant differences in medications [7]. Asian immigrants to the US may have different disease behaviors and clinical outcomes compared with those born in the US, regardless of race. Clinical trials of IBD medications predominantly include white patients, and guidelines are based on data from a majority of white patients $[4,13]$. Given the rising incidence of IBD in Asians, it is important to understand the similarities and differences of IBD between Asian and white patients, both early in disease course and longitudinally, in order to ensure appropriate management.

In order to better understand disease characteristics, medication use patterns, and disease activity over time among Asians in the US, we used the Sinai-Helmsley Alliance for Research Excellence (SHARE) cohort, a large prospective multi-center cohort, to identify differences between whites, US-born Asians, and Asian immigrants to the US.

\section{Methods}

\section{Data Source}

The SHARE assembled a prospective observational cohort of patients with IBD [14]. The cohort was established with the goal of creating a database of clinical information as well as a repository of biological specimens for genetic, molecular, and microbiological research to better understand IBD. Patients were recruited from 7 US academic centers: Cedars-Sinai Medical Center, Los Angeles, CA; Massachusetts General Hospital, Boston, MA; Mayo Clinic, Rochester, MN; Mount Sinai Hospital, New York City, NY; University of Chicago Medical Center, Chicago, IL; University of North Carolina Hospitals, Chapel Hill, NC; and Washington University Medical Center, Saint Louis, MO, USA. The institutional review boards of all institutions approved the study.

Patients who were 18 years or older, were able to provide consent, and had a confirmed diagnosis of IBD by their medical records were eligible for inclusion in the SHARE cohort. Consented patients provided demographic information, medical history, surgical history, family history, medication use, extraintestinal manifestations, and the patient health questionnaire (PHQ)-8 survey for depression via a baseline interview with a study coordinator. Aggressive disease was defined as stricturing or penetrating disease for $\mathrm{CD}$ and pancolitis for ulcerative colitis (UC). A biologic was defined as infliximab, adalimumab, certolizumab, golimumab, vedolizumab, or ustekinumab. Depression was defined as a PHQ- 8 score of $\geq 5$ [15]. Disease characteristics, as defined by the Montreal classification, medication use, extraintestinal manifestations, and laboratory results, were obtained from the medical record. A modified Harvey-Bradshaw Index or Simple Clinical Colitis Activity Index was completed during each study visit. Remission was defined as a Harvey-Bradshaw Index $<5$ or a Simple Clinical Colitis Activity Index of $\leq 2[16,17]$.

Patients were followed prospectively with follow-up questionnaires, similar to the baseline questionnaire, administered either on the phone, via the Internet, or during a subsequent clinic visit. In addition to updated information from the baseline study visit, patients were asked if they had a hospitalization, for any reason, or surgery on their bowels since their last visit.

\section{Statistical Analysis}

We determined demographics, disease behavior, extent, and medical history for enrolled subjects at baseline stratified by race and immigration status: white, overall Asian, immigrant Asian, and US-born Asian. We used bivariate analyses as appropriate to determine associations at baseline. We performed logistic regression models to determine odds of immunosuppression at baseline after adjusting for age, sex, disease duration, type of IBD, and aggressive disease, which are confounders that were selected a priori based on clinical judgement. We used binomial regression to estimate risk ratios and $95 \%$ confidence intervals (CIs) for 5 distinct outcomes at follow-up: new IBD-related surgery, new hospitalization, new prescriptions for biologics or steroids, and relapse by disease activity index. All models were adjusted for disease behavior and extent by the Montreal classification and remission status at baseline, as well as confounders selected a priori based on clinical judgement. The binomial regression models were stratified by IBD subtype (CD or UC). All analyses were performed in Stata 14.0 (College Station, TX, USA).
Kochar et al. 
Table 1. Baseline demographics and disease characteristics for patients with IBD

\begin{tabular}{|c|c|c|c|c|}
\hline & $\begin{array}{l}\text { Whites } \\
(n=5,223)\end{array}$ & $\begin{array}{l}\text { US-born Asians } \\
(n=35)\end{array}$ & $\begin{array}{l}\text { Asian immigrants } \\
(n=81)\end{array}$ & $p$ value \\
\hline Crohn disease, $\%$ & 64 & 40 & 51 & 0.001 \\
\hline Mean age (SD), years & $41(15)$ & $35(10)$ & $40(13)$ & 0.004 \\
\hline Mean age at diagnosis (SD), years & $29(14)$ & $25(11)$ & $33(12)$ & 0.056 \\
\hline Female, \% & 52 & 49 & 48 & 0.705 \\
\hline Mean disease duration (SD), years & $12(11)$ & $10(7)$ & $7(7)$ & $<0.001$ \\
\hline Mean follow-up (SD), months & $23(10)$ & $25(10)$ & $24(11)$ & 0.576 \\
\hline Current smokers, \% & 21 & 0 & 0 & 0.099 \\
\hline Remission $^{\mathrm{a}}, \%$ & 58 & 62 & 67 & 0.238 \\
\hline History of IBD surgery, \% & 40 & 16 & 25 & 0.001 \\
\hline Location of Crohn disease, $\%$ & & & & 0.099 \\
\hline Ileal & 26 & 25 & 13 & \\
\hline Colonic & 19 & 42 & 25 & \\
\hline Ileocolonic & 55 & 33 & 63 & \\
\hline Upper GI disease & 5 & 8 & 8 & 0.765 \\
\hline Behavior of Crohn disease, $\%$ & & & & 0.514 \\
\hline Inflammatory & 48 & 58 & 55 & \\
\hline Stricturing & 29 & 17 & 18 & \\
\hline Penetrating & 24 & 25 & 28 & \\
\hline Perianal phenotype, $\%$ & 18 & 33 & 33 & 0.027 \\
\hline Perianal procedure, $\%$ & 17 & 9 & 20 & 0.373 \\
\hline Extent of ulcerative colitis, \% & & & & 0.954 \\
\hline Proctitis & 13 & 10 & 13 & \\
\hline Left-sided colitis & 30 & 29 & 34 & \\
\hline Extensive/pancolitis & 58 & 62 & 53 & \\
\hline
\end{tabular}

SD, standard deviation; IBD, inflammatory bowel disease; GI, gastrointestinal. ${ }^{\text {a }}$ Remission is defined as a modified Harvey-Bradshaw Index score $<5$ or a Simple Clinical Colitis Activity Index score $\leq 2$.

\section{Results}

There were 5,223 white patients, 35 US-born Asians, and 81 Asian immigrants in this cohort (Table 1). Of those who were foreign born, 41 (51\%) were born in South Asian countries (India, Pakistan, Nepal, and Bangladesh), and 21 (26\%) were born in East Asian countries (China, Hong Kong, Taiwan, North Korea, South Korea, and Japan). Patients were 52\% female in the white cohort, $49 \%$ female in the US-born Asian cohort, and $48 \%$ female in the Asian immigrant cohort $(p=0.705)$. The mean age at diagnosis was 29 years for white patients, 25 years for US-born Asians, and 33 years for Asian immigrants ( $p=$ 0.056). The mean duration of disease at baseline enrollment was 12 years for white patients, 10 years for US-born Asians, and 7 years for Asian immigrants $(p<0.001)$. In this cohort, $64 \%$ of the white patients, $40 \%$ of the US-born Asians, and $51 \%$ of the Asian immigrants had CD $(p<$ 0.001 ). Follow-up data were available for an average of 23 months on $73 \%$ of white patients, $60 \%$ of US-born Asian patients, and $74 \%$ of Asian immigrant patients ( $p=0.576$ ).

There were no significant differences in CD location or behavior by the Montreal classification. Asians had significantly more perianal disease than white patients (33 vs. $18 \%, p=0.007)$. However, there were no significant differences in prior perianal procedures between the groups at baseline. There were no differences in UC extent between the 3 groups. At baseline, $58 \%$ of white patients, $62 \%$ of US-born Asians, and $67 \%$ of Asian immigrants were in remission by disease activity index score $(p=0.238)$. In this cohort, $40 \%$ of white patients, $16 \%$ of US-born Asians, and 25\% of Asian immigrants had an IBD-related surgery by the time of entry into the cohort $(p=0.001)$.

Data on medication use patterns are presented for all Asian patients compared with white patients because there were no significant differences between US-born Asians and Asian immigrants (Table 2). There were sig- 
Table 2. Medications ever used at baseline by patients with inflammatory bowel disease

\begin{tabular}{llllr}
\hline Medication, \% & $\begin{array}{l}\text { Whites } \\
(n=5,223)\end{array}$ & $\begin{array}{l}\text { US-born Asians } \\
(n=35)\end{array}$ & $\begin{array}{l}\text { Asian immigrants } \\
(n=81)\end{array}$ & $p$ value \\
\hline Oral mesalamine & 78 & 77 & 79 & 0.988 \\
Oral steroids & 85 & 84 & 76 & 0.106 \\
Thiopurines & 66 & 61 & 56 & 0.119 \\
Methotrexate & 18 & 9 & 16 & 0.353 \\
Anti-TNF agents & 61 & 34 & 42 & $<0.001$ \\
Vedolizumab & 3 & 0 & 0 & 0.626 \\
Ustekinumab & 1 & 0 & 0 & $<0.007$ \\
Narcotics & 46 & 29 & 25 & \\
\hline
\end{tabular}

nificant differences in immunosuppressive medication use between the groups. At baseline, 35\% of white patients and $16 \%$ of Asian patients had ever been treated with infliximab $(p<0.001)$, and $49 \%$ of white patients and $36 \%$ of Asian patients had ever been treated with adalimumab $(p=0.010)$. In this cohort, $66 \%$ of white patients and $57 \%$ of Asian patients had ever been treated with a thiopurine $(p=0.047)$. White patients were also more likely to have been on a narcotic compared with Asian patients ( 46 vs. $26 \%, p<0.001$ ). In a multivariable analysis, adjusting for age, sex, type of IBD, disease duration, and aggressive disease, Asian patients had less than half the odds of ever being treated with a biologic agent (OR: 0.45, 95\% CI: $0.30-0.67$ ) or narcotic (OR: $0.47,95 \% \mathrm{CI}$ : 0.30-0.74) compared with white patients (Table 3 ).

There were no significant differences in extraintestinal manifestations between US-born Asians and Asian immigrants (Table 4). Asians were more likely to have ocular manifestations compared with white patients (3.4 vs. $0.7 \%, p=0.022$ ). Asians were significantly less likely to screen positive for depression on the PHQ- 8 scale than white patients ( 25 vs. $35 \%, p=0.022$ ).

After adjusting for disease behavior and remission status at baseline, there were no differences in IBD-related surgery or hospitalization, new biologic or steroid prescription, or relapse rates by disease activity index between Asian patients and white patients at follow-up in both CD and UC (Table 5).

\section{Discussion}

We evaluated disease characteristics and outcomes of IBD in Asian patients compared with white patients in a large longitudinal cohort of IBD patients from referral centers across the US. Compared with white patients, we found that Asians were more likely to have perianal dis-
Table 3. Odds of medication use adjusting for age, sex, disease duration, aggressive disease ${ }^{\mathrm{a}}$, and type of inflammatory bowel disease

\begin{tabular}{lll}
\hline Asians (ref.: whites) & Odds ratio & $95 \%$ confidence interval \\
\hline Thiopurines & 0.78 & $0.53-1.15$ \\
Biologic agents $^{\mathrm{b}}$ & 0.45 & $0.30-0.67$ \\
Narcotics & 0.47 & $0.30-0.74$ \\
\hline
\end{tabular}

a Aggressive disease is defined as stricturing or penetrating disease for Crohn disease and pancolitis for ulcerative colitis. b Biologic agents include infliximab, adalimumab, certolizumab, golimumab, vedolizumab, and ustekinumab.

ease. However, they did not have more perianal procedures. After controlling for confounders, they were less likely to be treated with a biologic agent. Despite this, there were no significant differences in outcomes, such as surgery and hospitalization, over an average of 23 months of follow-up between Asian and white patients.

Our results are consistent with 2 prior systematic reviews demonstrating that Asians have high rates of perianal disease $[4,7]$. Both reviews also reported a lower rate of surgery among Asians with IBD, as we demonstrated in our analyses. However, we had more loss to follow-up among Asians with perianal disease than among those without. Perianal disease can be an indicator for a more progressive course of disease. Furthermore, perianal disease is a risk factor for significant depressive symptoms and suicidal ideation [18]. While we do not distinguish between fistulizing and nonfistulizing perianal disease, the relatively lower rate of perianal procedures suggests a predominance of nonfistulizing perianal disease. Nonfistulizing perianal disease alone is a risk factor for progression to fistulizing perianal disease [19]. One hypothesis is that the increased rate of perianal disease in Asians is re- 
Table 4. Extraintestinal manifestations ever reported by patients with inflammatory bowel disease

\begin{tabular}{|c|c|c|c|c|}
\hline Extraintestinal manifestation, \% & $\begin{array}{l}\text { Whites } \\
(n=5,223)\end{array}$ & $\begin{array}{l}\text { US-born Asians } \\
(n=35)\end{array}$ & $\begin{array}{l}\text { Asian immigrants } \\
(n=81)\end{array}$ & $p$ value \\
\hline Erythema nodosum & 0.5 & 0.0 & 0.0 & $\mathrm{~N} / \mathrm{A}$ \\
\hline Pyoderma gangrenosum & 0.4 & 0.0 & 0.0 & $\mathrm{~N} / \mathrm{A}$ \\
\hline Arthralgia & 12.4 & 5.6 & 5.0 & 0.256 \\
\hline Ocular manifestations & 0.7 & 5.6 & 2.5 & 0.035 \\
\hline Depression $^{\mathrm{a}}$ & 35.1 & 32.3 & 21.5 & 0.041 \\
\hline
\end{tabular}

N/A, not applicable. ${ }^{a}$ Defined by a patient health questionnaire- 8 score of $\geq 5$.

Table 5. Asians' risk of developing worse outcomes, adjusting for baseline disease behavior and remission status

\begin{tabular}{|c|c|c|c|c|}
\hline \multirow[t]{2}{*}{ Indicator of more aggressive IBD } & \multicolumn{2}{|l|}{ Crohn disease } & \multicolumn{2}{|l|}{ Ulcerative colitis } \\
\hline & $\begin{array}{l}\text { Asian risk ratio } \\
\text { (ref.: whites) }\end{array}$ & $95 \% \mathrm{CI}$ & $\begin{array}{l}\text { Asian risk ratio } \\
\text { (ref.: whites) }\end{array}$ & $95 \% \mathrm{CI}$ \\
\hline IBD-related surgery & 0.69 & $0.24-2.04$ & 0.91 & $0.30-2.70$ \\
\hline IBD-related hospitalization & 0.58 & $0.28-1.21$ & 0.83 & $0.45-1.54$ \\
\hline New biologic prescription & 1.99 & $0.96-4.11$ & 1.27 & $0.50-3.20$ \\
\hline New steroid prescription & 1.41 & $0.20-9.89$ & 1.11 & $0.16-7.90$ \\
\hline Relapse $^{\mathrm{a}}$ & 0.64 & $0.22-1.86$ & 0.86 & $0.39-1.86$ \\
\hline
\end{tabular}

IBD, inflammatory bowel disease; CI, confidence interval. ${ }^{\text {a }}$ Defined as a modified Harvey-Bradshaw Index $\geq 5$ for Crohn disease and a Simple Clinical Colitis Activity Index $>2$ for ulcerative colitis for those in remission at baseline.

lated to lower rates of biologic use. However, a European analysis demonstrated that the incidence of perianal fistulae did not decrease significantly in the biologic era [20]. Therefore, perianal disease in Asians may represent a distinct phenotype with a unique pathogenesis and not simply a marker for a more progressive disease course.

There are not many studies of genetics in non-Northern European ancestry cohorts in IBD. However, one studied group is African Americans, who are also described to have more perianal disease than whites [21]. Interestingly, like Asians, African Americans also have more proximal diverticulosis [22]. It may be informative to study whether African Americans and Asians share any genetic markers that manifest in similar gastrointestinal disease phenotypes. Given the rising incidence of IBD in Asians, differences in medication responses and the possibility of a different CD phenotype in Asians, genetic risk factors may play a role and need further study $[4,23]$. Furthermore, evaluating racial differences in perianal CD may help better characterize the pathogenesis of perianal disease.
Extraintestinal manifestations are also not well understood in IBD. Many studies report a lower rate of extraintestinal manifestations in Asians with IBD [3, 4]. Contrary to these reports, we found a higher rate of ocular manifestations among Asians. Supporting our findings, 2 studies from Northern India reported high rates of ocular manifestations in their cohort at 2 different time points, despite an overall low rate of all extraintestinal manifestations [24, 25]. An American study reported that African Americans with IBD had a higher rate of ocular manifestations [26]. This is interesting because African Americans also have higher rates of perianal disease, similar to Asians. Further work is needed to determine whether certain extraintestinal manifestations correlate with certain phenotypes of disease.

Depression is so strongly associated with active IBD that some describe it as an extraintestinal manifestation $[27,28]$. Significantly fewer Asian IBD patients were depressed at baseline. Even after controlling for confounders, Asian patients were much less likely to use narcotics. While this study cannot demonstrate causality, the asso-

Inflamm Intest Dis 2017;2:147-153 
ciation is notable. The population with less depression and less narcotic use had no significant differences in long-term outcomes, such as surgery, hospitalization, and relapse, despite more perianal disease. It is certainly possible that Asians are less depressed and have less narcotic use because they have less aggressive disease. However, it is also possible that depression and narcotic use are risk factors for worse outcomes, which has been demonstrated previously $[29,30]$.

The literature regarding racial and ethnic differences in health-care utilization and outcomes in IBD patients is conflicted, with some studies suggesting that there are disparities [31-33] and others suggesting that there are none $[10,34]$. Economic factors are thought to be the primary driver for the racial and ethnic disparities in health services utilization, including prescription medication use [35]. We were not able to control for socioeconomic factors. However, Asians have the highest median income of all racial groups in the US [36]. Additionally, all of the patients in this study were evaluated at tertiary care centers, where access to therapies, even for patients of lower economic resources, would be expected to be similar. This argues against low socioeconomic status contributing to differences in prescription patterns in this study and suggests that Asians may in fact have less aggressive disease not necessitating biologic therapy or may be less willing to initiate biologic therapy.

We are one of the few studies of longitudinal disease activity of Asians compared with whites. Comparing Asians and whites treated at the same centers can help minimize differences in prescribing patterns and management. Controlling for patient demographics and disease factors, we found that Asians were significantly less likely to be treated with biologic agents at baseline. Interestingly enough, in our longitudinal analysis, we did not find that Asians had a higher risk of worse outcomes, such as surgery, hospitalization, or relapse. This provides additional support that Asians may have a milder course of disease over time, despite similar disease behavior at diagnosis. Better understanding the Asian phenotype of IBD may help elucidate factors that prognosticate worse outcomes over time.

This longitudinal study of Asian and white IBD patients has several strengths. The data were validated from the medical record, with accurate depiction of disease phenotype. The study centers were geographically diverse across the US. This study also has limitations. The patients in this study were all treated in tertiary care centers, which may limit the external generalizability. Additionally, we do not have objective data in this cohort, such as

inflammatory markers, endoscopic evaluations, or pathology. We also do not have data on factors such as socioeconomic status and literacy that may affect healthcare disparities. Some studies suggest that IBD differs between the various Asian subgroups, so perhaps we should not be evaluating all Asians together [11, 12]. However, we did not have a large enough sample of Asians to perform an evaluation of Asian subgroups.

In summary, we found that Asians have more perianal disease than whites and were less likely to be treated with a biologic agent. However, there was no difference over time in outcomes, such as surgery, hospitalization, and relapse, between Asians and whites. Differences in disease phenotypes in Asians may reflect differences in genetics.

\section{Acknowledgements}

This research was supported by grants from the National Institutes of Health (P30DK07634 and T32DK07634) and by the Helmsley Charitable Trust.

\section{Statement of Ethics}

The authors have no ethical conflicts to disclose.

\section{Disclosure Statement}

All authors declare that they have no conflicts of interest.

References

Inflamm Intest Dis 2017:2:147-153 DOI: $10.1159 / 000484347$
1 Hoeffel EM, Rastogi S, Kim MO, Shahid H: The Asian Population: 2010. 2010 Census Briefs, 2012.

2 Ishige T, Tomomasa T, Hatori R, Tatsuki M, Igarashi Y, Sekine K, et al: Temporal trend of pediatric inflammatory bowel disease: analysis of national registry data 2004 to 2013 in Japan. J Pediatr Gastroenterol Nutr 2017; 65:e80-e82.

3 Ng WK, Wong SH, Ng SC: Changing epidemiological trends of inflammatory bowel disease in Asia. Intest Res 2016;14:111-119.

4 Hou JK, El-Serag H, Thirumurthi S: Distribution and manifestations of inflammatory bowel disease in Asians, Hispanics, and African Americans: a systematic review. Am J Gastroenterol 2009;104:2100-2109.

5 Ng SC, Leung WK, Shi HY, Li MK, Leung $\mathrm{CM}, \mathrm{Ng} \mathrm{CK}$, et al: Epidemiology of inflammatory bowel disease from 1981 to 2014: results from a territory-wide population-based registry in Hong Kong. Inflamm Bowel Dis 2016 22:1954-1960. 
6 Makharia GK, Ramakrishna BS, Abraham P, Choudhuri G, Misra SP, Ahuja V, et al: Survey of inflammatory bowel diseases in India. Indian J Gastroenterol 2012;31:299-306.

7 Shi H, Levy AN, Trivedi HD, Chan FK, Ng SC, Ananthakrishnan AN: Ethnicity influences phenotype and outcomes in inflammatory bowel disease: a systematic review and metaanalysis of population-based studies. Clin Gastroenterol Hepatol 2017, Epub ahead of print.

8 Malhotra R, Turner K, Sonnenberg A, Genta RM: High prevalence of inflammatory bowel disease in United States residents of Indian ancestry. Clin Gastroenterol Hepatol 2015;13: 683-689.

9 Benchimol EI, Mack DR, Guttmann A, Nguyen GC, To T, Mojaverian N, et al: Inflammatory bowel disease in immigrants to Canada and their children: a population-based cohort study. Am J Gastroenterol 2015;110:553-563.

10 Li D, Collins B, Velayos FS, Liu L, Lewis JD, Allison JE, et al: Racial and ethnic differences in health care utilization and outcomes among ulcerative colitis patients in an integrated health-care organization. Dig Dis Sci 2014;59:287-294.

11 Li BH, Guan X, Vittinghoff E, Gupta N: Comparison of the presentation and course of pediatric inflammatory bowel disease in South Asians with Whites: a single center study in the United States. J Pediatr 2013;163:12111213.

12 Chu HP, Logarajah V, Tan N, Phua KB: Paediatric inflammatory bowel disease in a multiracial Asian country. Singapore Med J 2013; 54:201-205.

13 Ha C, Ullman TA, Siegel CA, Kornbluth A: Patients enrolled in randomized controlled trials do not represent the inflammatory bowel disease patient population. Clin Gastroenterol Hepatol 2012;10:1002-1007; quiz e1078.

14 Ananthakrishnan AN, Kwon J, Raffals L, Sands B, Stenson WF, McGovern D, et al: Variation in treatment of patients with inflammatory bowel diseases at major referral centers in the United States. Clin Gastroenterol Hepatol 2015;13:1197-1200.
15 Kroenke K, Spitzer RL: The PHQ-9: a new depression diagnostic and severity measure. Psychiatr Ann 2002;32:509-515.

16 Harvey RF, Bradsaw JM: A simple index of Crohn's-disease activity. Lancet 1980;1:514.

17 Walmsley RS, Ayers RC, Pounder RE, Allan $\mathrm{RN}$ : A simple clinical colitis activity index. Gut 1998;43:29-32.

18 Mahadev S, Young JM, Selby W, Solomon MJ: Self-reported depressive symptoms and suicidal feelings in perianal Crohn's disease. Colorectal Dis 2012;14:331-335.

19 Herman Y, Rinawi F, Rothschild B, Nir O, Shamir R, Assa A: The characteristics and long-term outcomes of pediatric Crohn's disease patients with perianal disease. Inflamm Bowel Dis 2017;23:1659-1665.

20 Gottgens KW, Jeuring SF, Sturkenboom R, Romberg-Camps MJ, Oostenbrug LE, Jonkers $\mathrm{DM}$, et al: Time trends in the epidemiology and outcome of perianal fistulizing Crohn's disease in a population-based cohort. Eur J Gastroenterol Hepatol 2017;29:595-601.

21 Afzali A, Cross RK: Racial and ethnic minorities with inflammatory bowel disease in the United States: a systematic review of disease characteristics and differences. Inflamm Bowel Dis 2016;22:2023-2040.

22 Peery AF, Keku TO, Martin CF, Eluri S, Runge T, Galanko JA, et al: Distribution and characteristics of colonic diverticula in a United States screening population. Clin Gastroenterol Hepatol 2016;14:980-985.e981.

23 Yang SK, Hong M, Baek J, Choi H, Zhao W, Jung Y, et al: A common missense variant in NUDT15 confers susceptibility to thiopurine-induced leukopenia. Nat Genet 2014;46: 1017-1020.

24 Kochhar R, Mehta SK, Nagi B, Bhatia V, Goenka MK, Malik AK: Extraintestinal manifestations of idiopathic ulcerative colitis. Indian J Gastroenterol 1991;10:88-89.

25 Pokharna RK, Kabra PK, Sharma R, Kochar DK: Extraintestinal manifestations of idiopathic ulcerative colitis in northwestern India. Indian J Gastroenterol 2004;23:89-90.

26 Basu D, Lopez I, Kulkarni A, Sellin JH: Impact of race and ethnicity on inflammatory bowel disease. Am J Gastroenterol 2005;100:22542261.
27 Hauser W, Janke KH, Klump B, Hinz A: Anxiety and depression in patients with inflammatory bowel disease: comparisons with chronic liver disease patients and the general population. Inflamm Bowel Dis 2011;17:621632.

28 Ephgrave K: Extra-intestinal manifestations of Crohn's disease. Surg Clin North Am 2007; 87:673-680.

29 Mikocka-Walus A, Pittet V, Rossel JB, von Kanel R; Swiss IBD Cohort Study Group: Symptoms of depression and anxiety are independently associated with clinical recurrence of inflammatory bowel disease. Clin Gastroenterol Hepatol 2016; 14:829-835. e821.

30 Cross RK, Wilson KT, Binion DG: Narcotic use in patients with Crohn's disease. Am J Gastroenterol 2005;100:2225-2229.

31 Straus WL, Eisen GM, Sandler RS, Murray SC, Sessions JT: Crohn's disease: does race matter? The Mid-Atlantic Crohn's Disease Study Group. Am J Gastroenterol 2000;95: 479-483.

32 Nguyen GC, LaVeist TA, Harris ML, Wang MH, Datta LW, Brant SR: Racial disparities in utilization of specialist care and medications in inflammatory bowel disease. Am J Gastroenterol 2010;105:2202-2208.

33 Nguyen GC, Bayless TM, Powe NR, Laveist TA, Brant SR: Race and health insurance are predictors of hospitalized Crohn's disease patients undergoing bowel resection. Inflamm Bowel Dis 2007;13:1408-1416.

34 Lin KK, Sewell JL: The effects of race and socioeconomic status on immunomodulator and anti-tumor necrosis factor use among ambulatory patients with inflammatory bowel disease in the United States. Am J Gastroenterol 2013;108:1824-1830.

35 Wang J, Zuckerman IH, Miller NA, Shaya FT, Noel JM, Mullins CD: Utilizing new prescription drugs: disparities among non-Hispanic whites, non-Hispanic blacks, and Hispanic whites. Health Serv Res 2007;42:1499-1519.

36 United States Census Bureau: Median Household Income in the Past 12 Months (in 2015 inflation-adjusted dollars). American Community Survey, 2016. 